\title{
ADSORPSI-DESORPSI ZAT WARNA NAFTOL BLUE BLACK MENGGUNAKAN ADSORBEN HUMIN HASIL ISOLASI TANAH GAMBUT RIAU, SUMATERA
}

\author{
Silvia Riqotul Fuadah ${ }^{1}$, Maya Rahmayanti ${ }^{1}$ \\ ${ }^{1}$ Program Studi Kimia, Fakultas Sains dan Teknologi Universitas Islam Negeri Sunan Kalijaga, \\ Jl.Laksda Adisucipto, Yogyakarta 55281 Indonesia \\ silviariqotulfuadah@gmail.com
}

\begin{tabular}{|l|}
\hline Artikel Info \\
Diterima \\
tanggal \\
15.09 .2019 \\
Disetujui \\
publikasi \\
tanggal \\
31.10 .2019 \\
Kata kunci : \\
humin, naftol \\
blue black, zat \\
warna \\
\hline
\end{tabular}

\begin{abstract}
ABSTRAK
Telah dilakukan adsorpsi-desorpsi zat warna naftol blue black menggunakan adsorben humin hasil isolasi tanah gambut Riau, Sumatera. Metode adsorpsi belum sepenuhnya menyelesaikan masalah lingkungan karena adsorben yang sudah digunakan dapat menjadi limbah baru, sehingga diperlukan proses desorpsi agar adsorben dapat digunakan kembali. Nilai persen adsorpsi zat warna naftol blue black pada penelitian ini sebesar 75,91\%. Proses desorpsi menggunakan agen pendesorpsi $\mathrm{NaCl}$ dengan variasi konsentrasi $0,1,0,2,0,3$, 0,4, dan 0,5 M dan desorpsi zat warna naftol blue black optimum pada konsentrasi $\mathrm{NaCl}$ 0,3 $\mathrm{M}$ dengan persen desorpsi sebesar 11,65\%.
\end{abstract}

\section{ABSTRACT}

Adsorption-desorption of naphtol dye had been done by using humin adsorbent wich was taken from peat isolation in Riau, Sumatera. The adsorption method had not completely solved the environmental issue because the adsorbent that had been used could be a new waste, so the desorption process was needed for the adsorbent could be reused. The adsorption percent value of naphtol blue black dyes in this study was $75.91 \%$. The desorption process used $\mathrm{NaCl}$ with some concentration varieties of $0.1,0.2,0.3,0.4$ and $0.5 \mathrm{M}$, and desorption of optimum naphtol blue black dyes at a concentration of $0.3 \mathrm{M}$ with desorption yield percentage of $11.65 \%$.

\section{PENDAHULUAN}

Indonesia merupakan negara dengan kekayaan alam yang besar serta budaya yang beragam. Salah satu warisan kebudayaan nenek moyang yang sudah diakui sebagai warisan budaya dunia yaitu "Batik". Pertumbuhan dan perkembangan industri batik yang pesat memiliki dampak yang besar terhadap lingkungan dengan dihasilkannya limbah industri yang mengandung zat-zat kimia berbahaya. Limbah industri batik mengandung berbagai jenis pencemar, salah satu yang signifikan adalah kandungan zat warna. Zat warna apabila dibuang langsungtanpa melalui proses pengolahan limbah dapat mengakibatkan pencemaran lingkungan (Setyaningsih, 2007).

Beberapa metode yang dapat dilakukan untuk menanggulangi masalah limbah zat warna tersebut antara lain metode koagulasi, elektrokimia, ozonisasi, dan adsorpsi. metode 
alternatif dan efektif yang dapat dilakukan untuk menanggulangi limbah zat warna yaitu menggunakan adsorpsi. Adsorpsi merupakan peristiwa penyerapan suatu zat pada permukaan zat lain. Metode ini merupakan metode alternatif yang tidak memerlukan pre-treatment dan biaya yang relatif rendah (Park dkk, 2016).

Metode adsorpsi untuk pengolahan zat warna belum sepenuhnya efektif menyelesaikan permasalahan lingkungan karena mengakibatkan munculnya limbah adsorben yang sudah digunakan, sehingga diperlukan proses desorpsi zat warna agar adsorben dapat digunakan kembali (Peng dkk, 2012). Desorpsi dapat dilakukan dengan mengontakkan adsorben yang telah digunakan dengan larutan yang dikenal dengan agen pendesorpsi. Agen pendesorpsi dapat berupa asam, netral, dan basa (Wankasi, 2005).

Berdasarkan uraian di atas kebaharuan penelitian ini yaitu proses desorpsi zat warna naftol blue black pada adsorben humin. Zat warna naftol blue black merupakan senyawa anionik sehingga dapat menggunakan $\mathrm{NaCl}$ sebagai agen pendesorpsi. Desorpsi dilakukan untuk mengetahui pengaruh agen pendesorpsi dengan variasi konsentrasi sehingga dapat diketahui konsentrasi optimum dari proses desorpsi menggunakan agen pendesorpsi $\mathrm{NaCl}$.

\section{METODE}

\section{Alat dan Bahan}

Alat-alat yang digunakan adalah kertas saring biasa dan kertas saring whatsman 42 , labu ukur $250 \mathrm{~mL}$, labu ukur $50 \mathrm{~mL}$, pipet ukur $1 \mathrm{~mL}$, gelas beker $250 \mathrm{~mL}$, magnetic stirrer, hot plate, neraca analitik, sentrifuge, dan alat-alat analisis: Fourier Transform Infra Red (FTIR), dan spektrofotometer UV-Vis. Bahan-bahan yang digunakan adalah humin hasil isolasi tanah gambut Riau, Sumatera, $\mathrm{HCl} 1 \mathrm{M}, \mathrm{NaOH} 1 \mathrm{M}, \mathrm{NaCl}$ 0,1, 0,2, 0,3, 0,4, dan 0,5 M, HF 0,3 M, akuades, dan zat warna naftol blue black.

\section{Prosedur}

\section{Pembuatan larutan induk naftol blue black}

Sebanyak 0,25 g naftol, 0,75 g garam diazo jenis blue black, dan 0,125 g soda kustik ditimbang untuk dibuat larutan induk naftol blue black 1000 ppm. Kemudian soda kustik dilarutkan dengan akuades dan dipanaskan untuk melarutkan serbuk naftol. Selanjutnya dilarutkan garam diazo jenis blue black menggunakan akuades dalam labu ukur $50 \mathrm{~mL}$. Kemudian diambil $1 \mathrm{~mL}$ larutan garam diazo jenis blue black untuk dicampurkan kedalam larutan soda kustik dan naftol yang sudah dingin. Campuran ketiga bahan tersebut dimasukan 
kedalam labu ukur $250 \mathrm{~mL}$ dan diencerkan menggunakan akuades sampai tanda batas dan digojog sampai homogen.

\section{Penentuan panjang gelombang maksimum zat warna naftol blue black}

Panjang gelombang maksimum ditentukan dengan mengukur larutan 200 ppm pada rentang panjang gelombang 400-800 $\mathrm{nm}$ dengan menggunakan Spektrofotometer UV-Vis. Panjang gelombang dengan nilai absorbansi terbesar merupakan panjang gelombang maksimum. Panjang gelombang yang diperoleh digunakan untuk pengukuran berikutnya.

\section{Pembuatan kurva regresi linier zat warna naftol blue black}

Larutan induk 1000 ppm diencerkan menjadi 500 ppm, 400 ppm, 300 ppm, 200 ppm, dan 100 ppm, kemudian diukur absorbansinya dengan spektrofotometer UV-Vis pada panjang gelombang maksimum. Absorbansi yang diperoleh kemudian diplotkan kedalam grafik dengan hubungan antara konsentrasi vs absorbansi sehingga diperoleh persamaan dari grafik tersebut. Kemudian menentukan konsentrasi larutan sampel sebelum dan sesudah adsorpsi dengan persamaan yang telah diperoleh.

\section{Adsorpsi humin terhadap zat warna naftol blue black}

Adsorpsi zat warna naftol menggunakan $\mathrm{pH}$, konsentrasi adsorbat, dan waktu kontak optimum yang mengacu pada penelitian sebelumnya yang melakukan adsorpsi zat warna naftol menggunakan adsorben humin hasil isolasi tanah gambut sumatera (Larasati, 2018) dan sebanyak 1,5 gram humin dimasukkan ke dalam erlenmeyer 150ml dan larutan zat warna naftol sebanyak $150 \mathrm{ml}$ dengan $\mathrm{pH}$ optimum 6. Campuran disheker selama 60 menit kemudian disaring dengan kertas Whatman 42. Filtrat dianalisis dengan spektrofotometer UV-Vis sesuai panjang gelombang naftol blue black. Humin yang telah digunakan untuk mengadsorp zat warna naftol blue black dikeringkan pada suhu $80^{\circ} \mathrm{C}$ selama 2 jam. Padatan yang telah kering dikarakterisasi dengan FTIR.

\section{Desorpsi zat warna naftol blue black hasil adsorpsi}

Sebanyak $0,025 \mathrm{~g}$ humin yang telah mengadsorp zat warna naftol dilarutkan dalam 25 $\mathrm{mL} \mathrm{NaCl}$. Campuran digojok dengan kecepatan 125rpm dengan variasi konsentrasi 0,1, 0,2, 0,3, 0,4, dan 0,5 M selama 60 menit. Kemudian campuran disaring dan filtrat yang dihasilkan dianalisis dengan spektrofotometer UV-Vis sesuai panjang gelombang naftol blue black. 


\section{HASIL DAN PEMBAHASAN}

\section{A. Penentuan panjang gelombang maksimum dan kurva regresi linier dari zat warna naftol blue black}

Panjang gelombang maksimum ditentukan dengan menggunakan larutan zat warna naftol blue black pada rentang panjang gelombang 200 - $800 \mathrm{~nm}$. Berdasarkan pengukuran spektrofotometer UV-Vis pada penelitian ini, absorbansi tertinggi dihasilkan pada panjang gelombang 549,22 $\mathrm{nm}$.

Hasil persamaan regresi berdasarkan Gambar 2 yaitu $y=0,0014 x+0,0121$ dengan nilai koefisien korelasi $\left(\mathrm{R}^{2}\right)=0,986$. Nilai koefisien korelasi $\left(\mathrm{R}^{2}\right)$ yang diperoleh mendekati angka 1 yang menunjukkan bahwa persamaan regresi tersebut linier dan pengaruh konsentrasi terhadap absorbansi sebesar $98,60 \%$.

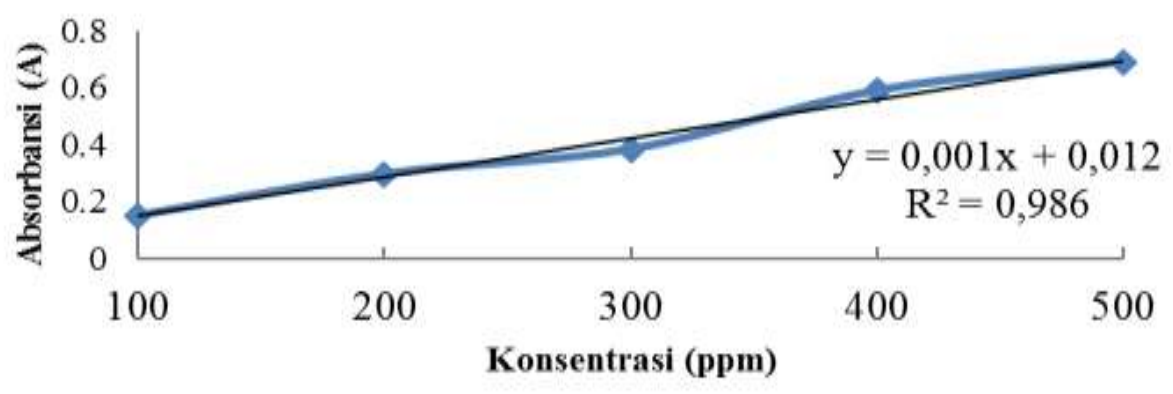

Gambar 2. Grafik hubungan konsentrasi Vs absorbansi larutan naftol blue black

\section{B. Adsorpsi zat warna naftol blue black oleh adsorben humin}

pH merupakan faktor yang penting dalam adsorpsi zat warna didalam larutan karena perubahan keasaman dapat menyebabkan perubahan muatan situs aktif pada permukaan adsorben. Berdasarkan penelitian sebelumnya (Larasati, 2018) menyatakan adsorpsi zat warna naftol optimum pada $\mathrm{pH}$ 2. Hal tersebut tidak sesuai dengan penelitian yang dilakukan karena pada pH 2 zat warna naftol blue black akan mengalami kerusakan akibat terurainya gugus aktif pada zat warna naftol blue black yang ditandai dengan adanya penggumpalan zat warna naftol blue black sehingga zat warna naftol tidak teradsorp secara maksimal.

Kemampuan adsorpsi pada penelitian ini optimum di pH 6 merujuk pada penelitian Yunita (2018) yang menggunakan zat warna naftol blue black untuk proses adsorpsi karena humin mengalami protonasi pada gugus $-\mathrm{COOH}$ dan $-\mathrm{OH}$ yang menyebabkan humin 
cenderung bermuatan parsial positif Reaksi yang terjadi disajikan pada persamaan (1) dan (2).

$$
\begin{array}{lll}
-\mathrm{COOH}+\mathrm{H}^{+} & \longrightarrow \\
-\mathrm{OH}+\mathrm{H}^{+} \longrightarrow & -\mathrm{COOH}_{2}^{+} \\
-\mathrm{OH}_{2}^{+}
\end{array}
$$

Proses adsorpsi mengalami penurunan pada $\mathrm{pH}$ diatas 6 disebabkan karena pada $\mathrm{pH}$ tersebut, zat warna naftol blue black mulai tidak stabil dan gugus $\mathrm{H}^{+}$pada humin akan cenderung mengalami deprotonasi sehingga menyebabkan muatannya negatif dan menjadikan interaksi yang dihasilkan antara zat warna naftol blue black dengan adsorben humin cenderung lemah dan adsorpsi menurun

\section{Karakterisasi humin sebelum adsorpsi, setelah adsorpsi, dan setelah desorpsi}

Karakterisasi humin menggunakan Fourier Transform Infrared (FTIR) untuk mengetahui gugus-gugus fungsional adsorben humin setelah dimurnikan, setelah proses adsorpsi, dan setelah proses desorpsi. Karakterisasi humin menggunakan FTIR dilakukan pada panjang gelombang 4000 - $400 \mathrm{~cm} 1$. Spektrum ketiga FTIR memperlihatkan beberapa pola serapan yang disajikan pada Gambar 3 .

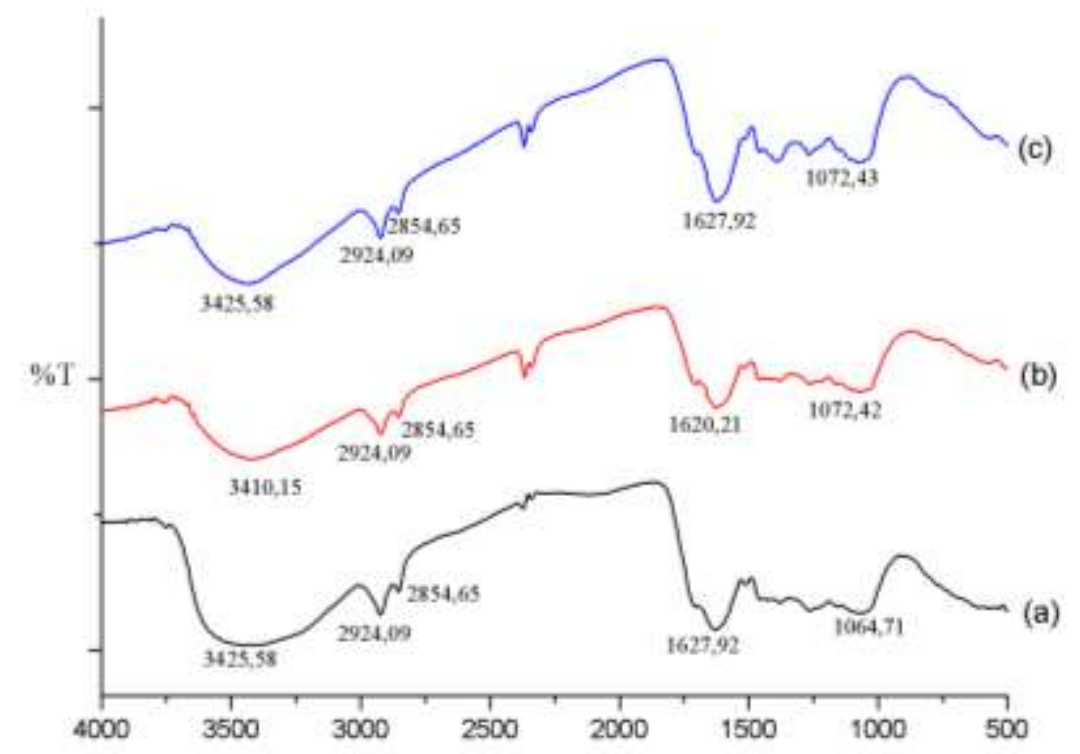

Gambar 3. Hasil Spektra FTIR Gugus Fungsional Humin (a) Sebelum Adsorpsi, (b) Setelah Adsorpsi, dan (c) Setelah Desorpsi 
Berdasarkan spektra FTIR yang dipaparkan dapat dilihat perbandingan bilangan gelombang antara adsorben humin sebelum adsorpsi, setelah adsorpsi, dan setelah desorpsi yang disajikan pada Tabel 1.

Tabel 1. Perbandingan bilangan gelombang antara adsorben humin sebelum adsorpsi, setelah adsorpsi, dan setelah desorpsi

\begin{tabular}{|c|c|c|c|}
\hline Jenis ikatan & 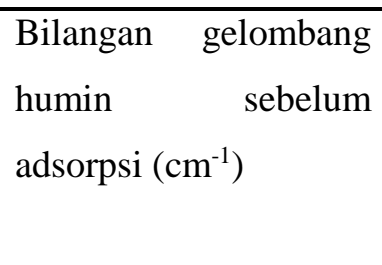 & $\begin{array}{l}\text { Bilangan } \\
\text { gelombang humin } \\
\text { setelah adsorpsi } \\
\left(\mathrm{cm}^{-1}\right)\end{array}$ & $\begin{array}{l}\text { Bilangan } \\
\text { gelombang humin } \\
\text { setelah desorpsi } \\
\left(\mathrm{cm}^{-1}\right)\end{array}$ \\
\hline Vibrasi ulur $\mathrm{OH}$ & 3425,58 & 3410,15 & 3425,58 \\
\hline Vibrasi ulur C-H alifatik & $2854,65-2924,09$ & $2854,65-2924,09$ & $2854,65-2924,09$ \\
\hline $\begin{array}{l}\text { Vibrasi ulur } \mathrm{C}=\mathrm{O} \text { dari } \\
-\mathrm{COOH}\end{array}$ & 1627,92 & 1620,21 & 1627,92 \\
\hline \multirow[t]{2}{*}{$\begin{array}{l}\text { Ikatan C-O karboksil } \\
\text { Vibrasi }-\mathrm{SO}_{3}\end{array}$} & 1064,71 & 1072,42 & 1072,42 \\
\hline & - & 1226 & - \\
\hline
\end{tabular}

\section{Desorpsi zat warna naftol blue black}

Desorpsi merupakan suatu peristiwa terlepasnya molekul, ion, atau partikel yang terserap oleh suatu padatan (Supriyanto, 2010). Desorpsi dilakukan apabila proses adsorpsi sudah mencapai titik jenuh dan tidak mampu menyerap adsorbat kembali. Desorpsi zat warna naftol blue black dilakukan untuk melepaskan zat warna naftol blue black dari adsorben humin sehingga dapat digunakan kembali.

Desorpsi dilakukan apabila proses adsorpsi sudah mencapai titik jenuh dan tidak mampu menyerap adsorbat kembali. Desorpsi zat warna naftol blue black dilakukan untuk melepaskan zat warna naftol blue black dari adsorben humin sehingga dapat digunakan kembali. Hasil desorpsi dengan variasi konsentrasi disajikan pada Gambar 3.

Berdasarkan Gambar 3 Persen desorpsi semakin meningkat seiring dengan bertambahnya konsentrasi agen pendesorpsi.Proses desorpsi mencapai konsentrasi maksimum pada konsentrasi $\mathrm{NaCl} 0,3 \mathrm{M}$ dengan persen desorpsi sebesar 11,65\%. Keberadaan $\mathrm{NaCl}$ pada larutan sebagai agen pendesorpsi sangat mempengaruhi zat warna naftol blue black karena kekuatan ion $\mathrm{Na}^{+}$dari $\mathrm{NaCl}$ akan melepaskan zat warna naftol blue black yang telah berinteraksi dengan adsorben humin. Persen desorpsi zat warna naftol blue black mengalami penurunan pada konsentrasi agen pendesorpsi sebanyak 0,4 M. Penurunan 
yang terjadi dikarenakan semakin berkurangnya ion-ion yang dapat menggantikan zat warna naftol blue black berinteraksi dengan adsorben humin

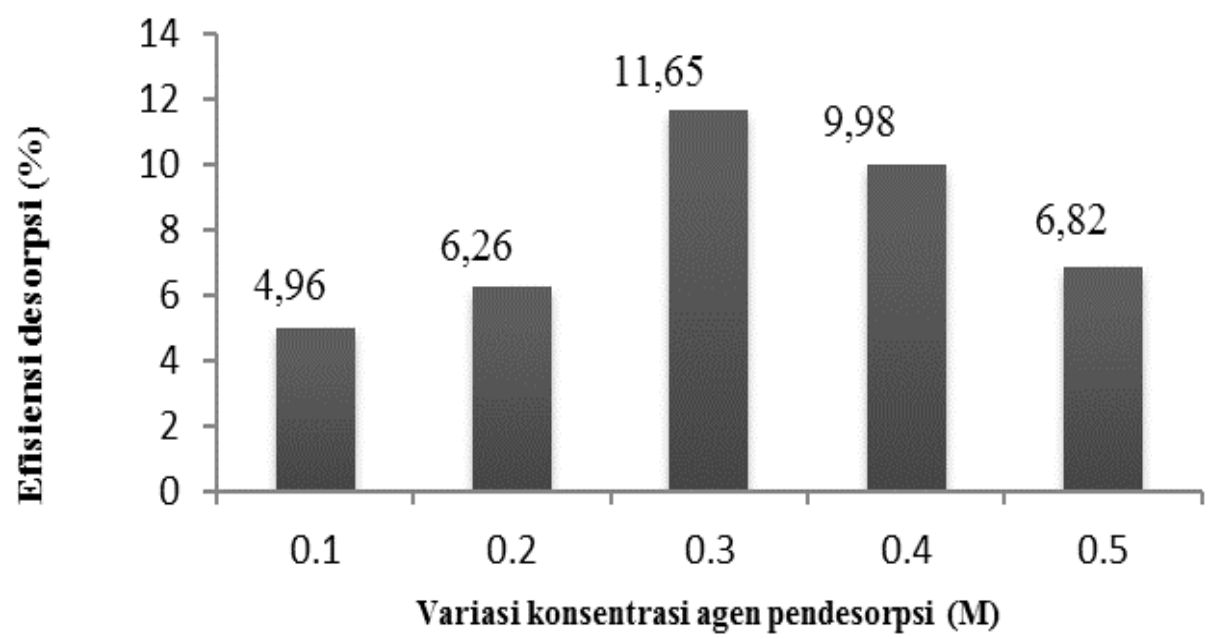

Gambar 3. Grafik efisiensi desorpsi zat warna naftol blue black pada adsorben humin

Konsentrasi optimum desorpsi yang sangat kecil mengindikasikan bahwa ikatan antara zat warna naftol blue black mempunyai ikatan yang kuat. Hal tersebut sesuai dengan penelitian sebelumnya yang menyebutkan bahwa adsorpsi zat warna naftol blue black yang terjadi merupakan adsorpsi kimia dengan energi adsorpsi 20,77 kJ/mol (Larasati, 2018).

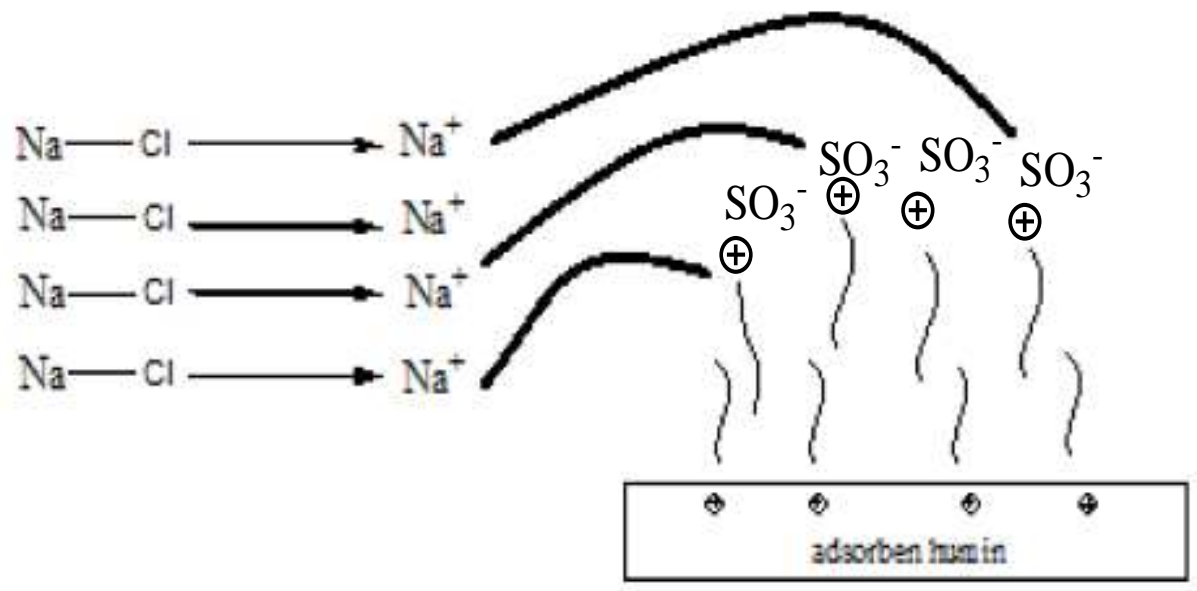

Gambar 4. Naftol blue black yang terdesorpsi dari adsorben humin lewat pertukaran ion 
Berdasarkan penelitian yang dilakukan dapat diketahui bahwa Interaksi yang terjadi pada adsorpsi zat warna naftol blue black melibatkan gaya elektrostatik yang dikenal dengan adsorpsi kimia (Oscik, 1982). Menurut Stum dan Morgan (1981) Gaya elektrostatik merupakan gaya yang diakibatkan karena adanya tarik menarik antara ion-ion yang bermuatan berlawanan. Gaya elektrostatik mempunyai ikatan yang kuat sehingga hal tersebut mengakibatkan ikatan yang terbentuk antara zat warna naftol blue black dengan adsorben humin sulit dilepaskan dan desorpsi yang dihasilkan tidak maksimal. Desorpsi yang kurang maksimal juga terjadi karena komposisi adsorben humin sangat mempengaruhi jumlah pelepasan zat warna naftol blue black sehingga $\mathrm{Na}^{+}$dari $\mathrm{NaCl}$ yang menarik ujung-ujung negatif dari zat warna naftol blue black lebih sedikit dari anion yang berada pada zat warna naftol blue black.

\section{KESIMPULAN}

Hasil karakterisasi dengan FTIR menunjukkan adsorben humin mengalami pergeseran pada bilangan gelombang sebelum adsorpsi, setelah adsorpsi, dan setelah proses desorpsi yang menunjukkan zat warna naftol blue black teradsorpsi dan terdesorpsi. Proses desorpsi zat warna naftol menggunakan agen pendesorpsi $\mathrm{NaCl}$ dengan variasi konsentrasi $0,1,0,2$, 0,3, 0,4, dan 0,5 M. Proses desorpsi optimum pada konsentrasi 0,3 M dengan persen desorpsi $11,65 \%$, dan pada konsentrasi $0,1 \mathrm{M}$ persen desorpsi sangat kecil yaitu hanya 4,96\%.

\section{DAFTAR PUSTAKA}

Larasati, Feni. 2018. Adsorpsi Zat Warna Naftol Menggunakan Adsorben Humin Hasil Isolasi Tanah Gambut Sumatera. Fakultas Sains dan Teknologi UIN Sunan Kalijaga: Yogyakarta

Oscik, J. 1982. Adsorption. Ellis Horwood Limited, England

Park, Min Chang, Han, J.,Chu ,K. H., Al-Hamadani,Y.A.J., Her, N., Heo, J. dan Yoon, Y. 2017. Influence of Solution pH, Ionic Strength, and Humic Acid on Cadmium Adsorption onto Activated Biochar: Experiment and Modelling.Journal of Industrial and Engineering Chemistry, 48, 186-193.

Peng dkk. 2011. Modifying $\mathrm{Fe}_{3} \mathrm{O}_{4}$ nanoparticles with humic acid for removal Rhodamin $\mathrm{B}$ in water.Epartement of Enviromental Science and Engineering Human Agricultur University. China 
Setyaningsih, H. 2007. Pengolahan Limbah Batik dengan Proses Kimia dan Adsorpsi Karbon Aktif. Tesis. Jakarta: Program Pasca Sarjana UI.

Stumm, W, and Morgan, J.J. 1981. Aquatic Chemistry. Jhon Wiley and Sons, New York.

Supriyanto dan Muzaky. 2010. Proses Desorpsi Logam Berat pada Sedimen Sungai Daerah Muria dengan Pelarut Asam. Pusat Teknologi Akselerator dan Proses Bahan BATAN; Yogyakarta.

Wang, Y., Li, L., Zhou, X., Shu, R., Ding, L., Yao, K., Lv, W., dan Liu, G. 2016. Impact of Humin an Soil Adsorption and Remidiation Of Cd(II), Pb(II), and Cu(II). School of Enviromental Scirnce and Engineering. Guangdong University Of Technology; China.

Wankasi, D., Horsfall, M., Jnr., dan Spiff, A. I. 2006. Desorption Of $\mathrm{Pb}^{2+}$ and $\mathrm{Cu}^{2+}$ from Nipa Palm (Nypa Fruticans Wurmb) Biomass. Journal of Biotechnology Vol. 4 (9). 923 927.

Yunita, Erni. 2018. Modifikasi Magnetit $\left(\mathrm{Fe}_{3} \mathrm{O}_{4}\right)$ Pada Asam Humat Hasil Isolasi Tanah Gambut Sumatera sebagai Adsorben Zat Warna Naphtol Blue B. Fakultas Sains dan Teknologi UIN Sunan Kalijaga: Yogyakarta. 